\title{
"Electro-clinical Syndromes" with onset in Paediatric Age: the highlights of the clinical-EEG, genetic and therapeutic advances
}

Pasquale Parisi ${ }^{1 *}$, Alberto Verrotti ${ }^{2}$, Maria Chiara Paolino ${ }^{1}$, Rosa Castaldo ${ }^{1}$, Filomena lanniello ${ }^{1}$, Alessandro Ferretti ${ }^{1}$, Francesco Chiarelli ${ }^{2}$ and Maria Pia Villa ${ }^{1}$

\begin{abstract}
The genetic causes underlying epilepsy remain largely unknown, and the impact of available genetic data on the nosology of epilepsy is still limited. Thus, at present, classification of epileptic disorders should be mainly based on electroclinical features. Electro-clinical syndrome is a term used to identify a group of clinical entities showing a cluster of electro-clinical characteristics, with signs and symptoms that together define a distinctive, recognizable, clinical disorder. These often become the focus of treatment trials as well as of genetic, neuropsychological, and neuroimaging investigations. They are distinctive disorders identifiable on the basis of a typical age onset, specific EEG characteristics, seizure types, and often other features which, when taken together, permit a specific diagnosis which, in turn, often has implications for treatment, management, and prognosis. Each electro-clinical syndrome can be classified according to age at onset, cognitive and developmental antecedents and consequences, motor and sensory examinations, EEG features, provoking or triggering factors, and patterns of seizure occurrence with respect to sleep. Therefore, according to the age at onset, here we review the more frequently observed paediatric electro-clinical syndrome from their clinical-EEG, genetic and therapeutic point of views.
\end{abstract}

Keywords: Electro-clinical syndrome, Paediatric Epilepsy, EEG, Epileptic Syndrome, ILAE classification

\section{Introduction}

Syndrome classification is not applicable to all patients with epilepsy, but only a limited number of patients [1]. In fact, the 1989 syndrome classification assigned, in each category, "other epilepsies not defined as syndromes", using, moreover, the terms "syndromes" and "epilepsies" almost interchangeably. The result was that the term "syndrome" took on a broad and very imprecise meaning, to the point where very specific and highly recognizable entities (such as childhood absence epilepsy) and poorly differentiated and not welldescribed epilepsies (such as cryptogenic parietal lobe epilepsy), tended to be treated as though they represented the same level of diagnostic precision.

\footnotetext{
* Correspondence: pasquale.parisi@uniroma1.it

'NESMOS Department, Chair of Pediatrics, Child Neurology, Faculty of Medicine and Psychology." "Sapienza" University, Via di Grottarossa, 10351039, Rome,00189, Italy

Full list of author information is available at the end of the article
}

Moreover, in the past, the term "idiopathic" was also used to convey the idea of a highly pharmaco-responsive form of epilepsy, whereas, in the new ILAE terminology, the implication that "idiopathic" confers the quality of "benign" is, now-days, intentionally discarded. Thus, as a variety of subtle cognitive and behavioral disorders are seen in association with idiopathic epilepsies, cause is no longer equated with prognosis.

In this respect, in fact, at the present time, it might be reasonable to include some of the traditional electroclinical syndromes (ECS) (such as, benign rolandic epilepsy, Panayiotopoulos syndrome, and benign occipital epilepsy of the Gastaut type), previously classified as "idiopathic", in the unknown category [2].

In addition, correlations between genotype and phenotype in ECS (table 1) are not so easy to establish, since genetic and non genetic factors likely play a role in determining the severity of ECS phenotype. On the other hand, the numerous and increasing discoveries on genetic origin are improving our knowledge, and it is
C Biomed Central

(c) 2011 Parisi et al; licensee BioMed Central Ltd. This is an Open Access article distributed under the terms of the Creative Commons Attribution License (http://creativecommons.org/licenses/by/2.0), which permits unrestricted use, distribution, and reproduction in any medium, provided the original work is properly cited. 
Table 1 Electro-clinical syndromes in paediatric age according to age at onset

\begin{tabular}{|c|c|}
\hline $\begin{array}{l}\text { A) Neonatal period: } \\
<44 \text { weeks of gestational age }\end{array}$ & $\begin{array}{l}\text { BFNE } \\
\text { EME } \\
\text { Ohtahara syndrome }\end{array}$ \\
\hline$\frac{\text { B) Infancy: }}{<1 \text { year }}$ & $\begin{array}{l}\text { Epilepsy of infancy with migrating focal seizures } \\
\text { West syndrome } \\
\text { MEl } \\
\text { Benign infantile epilepsy } \\
\text { Benign familial infantile epilepsy } \\
\text { Dravet syndrome } \\
\text { Myoclonic encephalopathy in non progressive disorders } \\
\text { FS+ (can start in childhood) }\end{array}$ \\
\hline$\frac{\text { C) Childhood: }}{1-12 \text { years }}$ & $\begin{array}{l}\text { FS+ (can start in infancy) } \\
\text { PS } \\
\text { Epilepsy with myoclonic atonic (previously astatic) seizures } \\
\text { BCECTS } \\
\text { ADNFLE } \\
\text { Late onset childhood occipital epilepsy (Gastaut type) } \\
\text { Epilepsy with myoclonic absences } \\
\text { Lennox-Gastaut syndrome } \\
\text { CSWS } \\
\text { LKS } \\
\text { CAE }\end{array}$ \\
\hline$\frac{\text { D) Adolescence: }}{12-18 \text { years }}$ & $\begin{array}{l}\text { JAE } \\
\text { JME } \\
\text { Epilepsy with generalized tonic-clonic seizures alone } \\
\text { Familial focal epilepsy with variable foci (childhood to adult) } \\
\text { Reflex epilepsies }\end{array}$ \\
\hline
\end{tabular}

BFNE: Benign familial neonatal epilepsy; EME: Early myoclonic encephalopathy; MEl: Myoclonic epilepsy in infancy; FS+: Febrile seizures plus; PS: Panayiotopoulos syndrome; BCECTS: Benign epilepsy with centrotemporal spikes; ADNFLE: Autosomal-dominant nocturnal frontal lobe epilepsy; CSWS: Epileptic encephalopathy with continuous spike-and-wave

during sleep; LKS: Landau-Kleffner syndrome; CAE: Childhood absence epilepsy; JAE: Juvenile absence epilepsy; JME: Juvenile myoclonic epilepsy.

hoped that this will be useful to define a more targeted therapeutic approaches for at least some of ECS.

One of the most distinctive and clinically salient dimensions for classifying ECS is based accordingly to their typical age at onset, as reported in table 1.

To provide epileptologists a comprehensive highlights of ECS aspects, among the currently ILAE recognized ECS (table 1), here we review, from an "electro-clinical", therapeutics and genetic points of view, the most frequently observed forms with onset in paediatric age (table 1).

\section{Early Infantile Epileptic Encephalopathy (EIEE) or Ohtahara Syndrome (OS)}

Early-infantile epileptic encephalopathy, also known as Ohtahara syndrome [3], is characterized by early onset of tonic spasms occurring with or without clustering, seizure intractability, a characteristic interictal burstssuppression (SB) pattern (Figure 1) on EEG persistently observed in both waking and sleeping states and a remarkable age-dependent evolution into the West syndrome (reported in $75 \%$ of cases) [4]. Prognosis is very poor with severe drug-resistance and psychomotor retardation.

The causes of EIEE are heterogeneous. Several brain malformations, neuronal migration disorders and metabolic disorders have been found as underlying causes of symptomatic OS [5]. Two causative genes are thought to be involved in the pathogenesis of cryptogenic cases of OS: the aristaless-related homeobox (ARX) and the syntaxin binding protein 1 (STXBP1) genes. The ARX gene is considered to have an important role in the neuronal proliferation, in differentiation of the embryonic brain, and in interneuronal migration, acting as a transcription factor in the development of GABAergic interneurons [6]. Phenotypes associated with ARX mutations include both malformative and non malformative syndromes.

Pleiotropic mutations of the ARX gene cause a variety of phenotypes that are considered to share a common pathological mechanism related to the structural and functional disturbance of interneurons, called "interneuronopathies" $[7,8]$. This hypothesis was supported by experimental data demonstrating that ARX protein deficiency results in the loss of GABAergic interneurons and anomalous distribution of residual cells in the cortex and basal ganglia [9]. Consequently, the GABAergic network dysfunction seems to play a crucial role in the pathogenesis of SB and in the hypsarrhythmic pattern. STXBP1, or MUNC18-1 gene encodes syntaxin binding protein 1, a neuron-specific protein that is essential for synaptic vesicle release $[10,11]$. A recent study showed that mutations in STXBP1 are not limited to patients with OS, but are also present in patients with an early- 


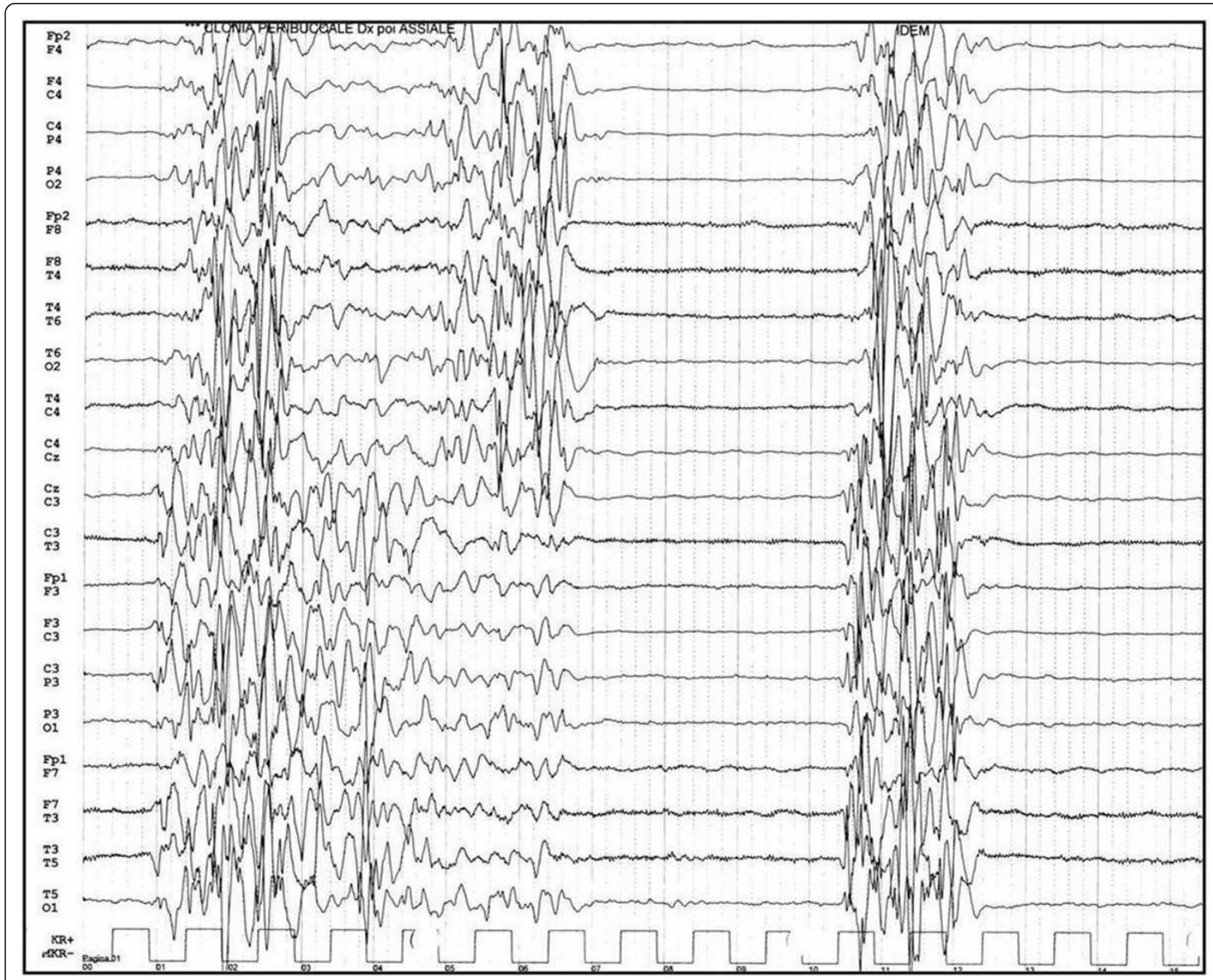

Figure 1 EEG pattern of suppression burst.

onset epileptic encephalopathy which do not fit into either OS or WS. This strongly supports the hypothesis that mutations in STXBP1 could cause a many kinds of epileptic disorders [12,13].

Although EIEE is usually characterized by drug resistance, some specific treatments have been reported to be effective, such as ketogenetic diet [14], liposteroid administration [15], zonisamide (ZNS) [16], high-dose phenobarbital (PB) [17], levetiracetam (LEV) [18], and vigabatrin (GVG) [19]. Selected patients could benefit from epilepsy surgery [20].

A similar syndrome, Early Myoclonic Encephalopahty (EME) has an onset within the first few weeks of life. EME has been associated primarily to metabolic disorders while EIEE is more likely associated to structural brain abnormalities. This syndrome differs from EIEE for the main type of clinical seizure observed: EME patients have fragmentary myoclonus while EIEE patients have epileptic spasms. EEG in EME shows a suppression-burst pattern less persistent than the one seen in EIEE. [3].

\section{Benign Familial Neonatal (BFNS) or Infantile (BFIS) or Neonatal-Infantile (BFNIS) Seizures}

BFNS (also known as Benign Familial Neonatal Convulsions) is a rare, monogenic, autosomal-dominant, benign familial epilepsy syndrome [21]. It is characterized by unprovoked and brief cluster of focal tonic-clonic convulsions occurring within the first days of life and frequently flowing into status epilepticus. No specific EEG trait characterizes BFNS: interictal EEG is most commonly normal, and if present, anomalies are usually transient $[1,22]$. The majority of individuals with BFNS can be kept seizures-free by using PB. Seizures disappear spontaneously within 2 months of life. Hovewer, about $10 \%-15 \%$ of children with BFNS develop seizures later 
in life with a variable age of onset and duration; in this eventuality, seizures are mainly generalized tonic or tonic-clonic seizures, and EEG may be characterized by centro-temporal spikes and sharp waves or benign epilepsy with centrotemporal spikes [23].

BFNS is linked to mutations in $\mathrm{KCNQ} 2$ and $\mathrm{KCNQ} 3$ genes [24], which are members of a family of voltagegated potassium channel genes (KCNQ1-5). They encode the voltage-gated Kv7.2 and Kv7.3 channels that produce a neuronal $\mathrm{M}$-current (muscarinic-regulated potassium current) which limits the repetitive firing of many neurons. More than 60 mutations have been described in BFNS families, with the majority involving KCNQ2.

No major phenotypic differences are observed between patients with BFNS caused by a KCNQ2 mutation and those with BFNS caused by a KCNQ3 mutation. Penetrance is incomplete (85\%); anticipation has not been observed [21]. The majority of newborns diagnosed with BFNS have an affected parent; however, also sporadic BFNS have been reported. In BFNIS, seizures appear in neonates, and in BFIS they begin between the 3rd and the 12th month of life.

Most of children with BFNS can keep seizure free by using PB (20 mg/kg as loading dose and $5 \mathrm{mg} / \mathrm{kg} /$ day as maintenance dose). In some cases have been used other anti-epileptic drugs (AEDs) like carbamazepine (CBZ), phenytoin (PHT), valproic acid (VPA), clonazepam (CZP), midazolam and GVG. Retigabine, selectively enhancer of potassium channels, is being tested as an adjunctive therapy in individuals with partial onset seizures [25]. Treatment is theoretically unnecessary for BFNIS and BFIS, but as seizures appear in cluster, it may be necessary to treat them. BFNIS condition could have some clinical and genetic features overlapping with BFIS, which is a dominant idiopathic epilepsy with partial and secondarily generalized seizures with age of onset between 3 and 12 months. Moreover, a mechanism that can explain that epileptic spells in BFNIS occur almost exclusively during the first days to months of life has recently been proposed [26]. BFIS is a genetically heterogenous condition with loci mapped to chromosomes 19 and 16. Mutations in the voltage-gated sodium channel alpha2 subunit (SCN2A) gene on chromosome 2 were recently identified in families affected by neonatal and infantile seizures (benign familial neonatal-infantile seizures, BFNIS) with typical onset before 4 months of life. Striano et al reported a novel SCN2A mutation in family with benign familial infantile seizures describing three affected individuals over three generations. Genetic study in this family revealed a novel heterozygous mutation c.3003 T > A in the SCN2A gene. Comparative analysis of different sodium channel alpha subunits indicates that the mutated residue is highly conserved throughout the evolution, suggesting an important functional role for this domain. The identification of SCN2A mutations in families with only infantile seizures indicated that BFNIS and BFIS show overlapping clinical features [27].

\section{West Syndrome and Infantile Spasms}

West syndrome (WS), also called Infantile Spasms (IS) or Salaam Spams/Tics, show an incidence which is estimated about 0,16-0,42 per 1000 live births [28]. In the first description, it was characterized by a famous triad that consists of seizures (so-called IS: generally consisting of, sudden, bilaterally and symmetrical, flexor, extensor or mixed type, spasms of the neck, trunk and extremities), characteristic abnormalities to the electroencephalography (hypsarrhytmia) and psychomotor retardation. The causes of this syndrome are heterogeneous and it can be divided in three principal groups: symptomatic, cryptogenetic and idiopathic. In the symptomatic group the epileptic desease is associated with various brain damage due to prenatal, perinatal and postnatal causes.

WS occurs in the first year of life, with a peak age at 5 months, seizures are heterogeneous and occur at awakening and during crying [29].

In 1950 Gastaut and co-workers described the EEG features associated with WS and then Gibbs and others conied the term hypsarrhythmia to define an EEG characterized by "random high voltage slow waves and spikes, that vary from moment to moment in duration and in location: at the onset, they appear to be focal and then they seem to originate from multiple foci; in few cases the spike discharge becomes generalized" [30].

Stromme and Weaving found mutations of two genes, ARX and STK9, in patients with X-linked familial West syndrome [31,32]. A polyalanine expansion mutation of the ARX gene has also been found in a patient with sporadic cryptogenetic WS [33]. A new STXBP1 mutation on cromosome $9 \mathrm{q} 34.11$ in a patients affected by WS without transition from OS has been reported [34]. Recently, a de novo deletion of 16p13.11 (previously suggested as risk factor for mental retardation and multiple congenital anomalies), in a patient with significant developmental delay, facial dysmorphism and WS, has been reported [35].

Many new therapeutic options have been tried: GVG, ZNS, nitrazepam (NZP), methisergide, LEV, topiramate (TPM), lamotrigine (LTG), pyridoxine, ketogenic diet, immunoglobulin therapy, felbamate (FLB), and thyrotropin-releasing hormone [36,37]. ACTH is generally estimated to be more effective than corticosteroids and it appears to positively alter long-term prognosis in the criptogenetic cases more than in the symptomatic ones [38]. 
GVG has been considered the drugs of first choice for patients affected by IS associated with tuberous sclerosis, as well as with Focal Cortical Dysplasia (FCD), and may also be a second-line agent for the treatment of other symptomatic IS. The efficacy of GVG is increased with high doses (100-150 mg/Kg/day) compared with the standard doses (40-100 mg/Kg/day) [39]. Unfortunately, GVG- related rethinopathy represents a limit for its use $[40,41]$. Brief period and low dose to minimize the probability of visual field defect GVG related has been suggested [42] and, in case of lack of improvement, GVG should be discontinued after 12 weeks [43].

\section{Dravet Syndrome (DS) and Genetic Epilepsy with Febrile Seizure Plus (GEFS+)}

GEFS+ is a familial autosomal-dominant epileptic syndrome with a large pattern of intra and extrafamilial phenotypic variability. Patients with GEFS+ may suffer from febrile seizures (FS) above the 6th year of age (called febrile seizures plus, FS+) and also afebrile myoclonic, absence, atonic, or partial seizures may appear [44]. FS and FS+ represent the milder form of GEFS+, whereas "severe myoclonic epilepsy of infancy" (SMEI) represent the most severe form. SMEI is an epileptic encephalopathy starting during the first year of life, especially around the 6th month, with recurrent and long-lasting febrile seizures, also as febrile status epilepticus. Drug-resistant myoclonic, complex partial, and atypical absence seizures can appear after the 12 months of life. Hot water seizures and photosensitivity are present in about $50 \%$ of the patients [44]. Regression of the normally acquired mental capacities may start from the 2nd year, often related to the episodes of status epilepticus [44]. Interictal myoclonus, ataxia and piramidal signs may complete the clinical picture. Japanese authors described patients with uncomplete SMEI phenotype, and have named these variants as borderline severe myoclonic epilepsy of infancy (SMEB) and intractable childhood epilepsy with generalized tonicclonic seizures (ICE-GTC) [45,46]. In GEFS+, SMEI, SMEB, and IGE-GTC mutations in the voltage gated sodium channel alpha1 subunit (SCN1A) gene have been discovered. SCN1A gene (Chromosome 2q24.3) is mainly expressed in the cerebral tissue and is implicated in generation and propagation of action potentials [47]. About $10 \%$ of GEFS+ patients have SCN1A mutation. In SMEI patients mutations falling in the encoding exons, which are de novo in $95 \%$, are present in about $80 \%$ of cases, and they include missense (39\%), nonsense (22\%), frameshift (19\%), splice site (10\%), genomic rearrangements (deletions, duplications, amplifications, translocations) (7\%), in-frame deletions (2\%), and other types (silent, complex mutations; $1 \%$ ) of mutations $[48,49]$.
Till now, in Dravet syndrome, hundreds of mutations were found in SCN1A, while only few mutations were identified in the paralogue gene, SCN2A, which encodes the alpha2 subunit, that is associated with BFNIS and BFIS, and other various intractable childhood epilepsies [50,51]. Mutations of SCN1B gene (voltage-gated sodium channel beta1 subunit) and GABRG2 gene (GABA receptor gamma2 subunit) were identified in a few families with GEFS+ spectrum [52,53].

A number of AEDs such as VPA, clobazam (CLB), TPM and LEV, are reported to be efficacious in DS [54,55]; VPA is used as a first-line agent to prevent the recurrence of febrile seizures and oral/nasal/rectal benzodiazepine is used for any long-lasting seizures, but these agents are most often insufficient. LTG, CBZ, and high doses of intravenous PB should be avoided because they may worsen seizures. TPM, LEV, bromide, and the ketogenic diet may provide substantial efficacy as adjunctive therapy/procedure [56]. Chiron reported the efficacy of stiripentol, a P450 inhibitor, used with VPA and a benzodiazepine [57]. Alternative therapies such the ketogenic diet, with controversial results, have been tried $[54,55]$.

Prolonged treatment with sodium channel-inhibiting AEDs may aggravate the disease course or lead to severe refractory status epilepticus $[58,59]$.

\section{Early-Onset Absence Epilepsy (EOAE)}

Absence seizures are epileptic manifestations that may start in children typically between the $4^{\text {th }}$ and the 10th year of age (Childhood Absence Epilepsy, CAE). Less commonly, absence seizures may arise before the 4th year of age (Early-onset Absence Epilepsy), and may be associated with other neurological disorders (other types of seizures, developmental delay, and movement disorders) [60]. Recently it has been suggested that Earlyonset pure absence epilepsy (EOAE) is a distinct epilepsy characterized by absences starting from a few months to 4 years of age, normal early psychomotor development, good AEDs seizure control and normal intellectual outcome [61].

Mutations in three different genes have been reported in children with absence seizures: anomalies of GABRG2 gene have been described in patients with febrile seizures and CAE $[62,63]$, and mutations in SCN1B and SCL2A1 genes have been reported in children with EAOE with [64] or without [65] febrile seizures. SCL2A1 gene encodes glucose transporter type 1 (GLUT1), a glucose transporter across the blood-brain barrier; SCL2A1 is responsible for the GLUT1 deficiency syndrome (infantile-onset epilepsy with heterogeneous type of seizures, complex movement disorders, ataxia, intellectual disability, macrocephaly, and hypoglycorrhachia) [66], and a large phenotypic spectrum 
characterized by normal glycorrhachia, movement disorders, often normal mental capacities, and seizures, in particular absence seizures [67]. Starting from these observation Suls et al. have found mutations in SCL2A1 gene in $12 \%$ of a cohort of 34 children with EOAE; the only clinical feature that can allow to differ children with EOAE from chidlren with CAE is the earlier age of onset. In addition, the authors preliminarily reported a marked reduction of epileptic activity at EEG in two of the mutated patients receiving ketogenic diet. In fact, it is of note that ketogenic diet may control seizures in cases of GLUT1 deficiency syndrome [65]. Lastly, a recent study performed by the same group of authors demonstrated that the epileptic phenotypic spectrum of GLUT1 deficiency is greater than previously recognized. In fact the authors have reported 12 patients with SCL2A1 mutations and epilepsy, including absence epilepsies with onset from early childhood to adult life, and various common forms of Idiopathic Generalized Epilepsy [68].

Recently, mutations in SLC2A1 gene leading to reduced function of GLUT1, the molecule transporting glucose across the blood-brain barrier, have been found in a significant proportion of children with absences starting before 4 years of age [65]. VPA monotherapy should represent the first-line treatment because it controls absences in the majority of cases [60,69]. Ethosuximide (ESM) had been previously used in some patients with a good seizure control [70]. Benzodiazepines are also effective to achieve seizure control, but they may induce tolerance and adverse effects $[65,70]$.

\section{Panayiotopoulos Syndrome}

Panayiotopoulos syndrome [PS] is characterised by seizures, often prolonged, with predominantly autonomic symptoms, and by an EEG that shows shifting and/or multiple foci, often with occipital predominance" [71]. PS occurs in children who are otherwise normal and, even after the most severe seizures and autonomic status epilepticus, the patient is normal and does not show any residual neurological or mental abnormalities. Accordingly, severe case of PS showed the apparent lack of consequences on the cognitive functions (Full Scale IQ = 106 at WISC-R) and normal sleep macrostructure profile in all night polysomnographic recording [72].

Previously considered as occipital epilepsy [73], PS has recently re-classified as "Autonomic Epilepsy" due to prominent autonomic manifestation which frequently represent the main (or sole) ictal epileptic semeiology [72,74-76].

Generally, age at onset is between 1 and 14 years (with 13\% in the youngest age group of 3-6 years) and most individuals have their first seizure around the age of 5 years. This syndrome (affecting males and females of all races almost equally) is considered the most common of benign childhood partial seizures after Rolandic epilepsy.

Unilateral deviation of the eyes with or, rarely, without ictal vomiting is the commonest ictal manifestation after emesis, occurring in around two thirds of seizures $(60 \%$ $80 \%)$. Seizures usually occur during nocturnal sleep, particularly the early part of sleep, or brief daytime naps. In nearly all seizures, consciousness is initially intact but becomes impaired as the seizure progresses, with the child becoming confused or unresponsive [77]. All functions of the autonomic nervous system can be affected, such as emesis, pallor, mydriasis, miosis, cardiorespiratory and thermoregulatory alterations, incontinence of urine and/or faeces, hypersalivation and modifications of intestinal motility; cardiorespiratory arrest and convulsive status epilepticus are exceptional [78].

The duration of the seizures is usually longer than 10 min [79]. Approximately half (44\%) of them last from 30 min to many hours, developing an autonomic status epilepticus [75,79]. Interictal EEG shows occipital spikes (70\%) although multifocal spikes with high amplitude sharp-slow wave complexes at various locations represent the most common EEG feature. Remarkably, the clinical manifestations are irrespective of EEG locations and despite similar clinical manifestations, there is a significant EEG variability from normal to abnormal EEG findings, sometimes in the same patient at different times. From a genetical point of view there are no available data, as well as about anticonvulsant therapy due to sporadic (and often not recognized) occurrence of seizures. Livingston $\mathrm{JH}$ et al described 2 families harboring a novel SCN1A mutation, one of whom had Panayiotopoulos syndrome and the other a phenotype consistent with generalized epilepsy with febrile seizures plus. The author argued that SCN1A mutations may cause susceptibility to an idiopathic focal epilepsy phenotype, the final phenotype depending on other (genetic or non genetic) factors [80]. Martín Del Valle F et al present two cases of Panayiotopoulos syndrome in two monozygotic twins, without SCN1A alteration, suggesting a genetic origin, with SCN1A associated with the outcome but not with the development of this syndrome [81].

As usually there is no need to start with anticonvulsant therapy, there are scarce available data about the efficacy of AEDs. In any case, recently, LEV showed good results in PS patients [82].

\section{Lennox-Gastaut Syndrome}

As regards the etiology, LGS (a rare epileptic encephalopathy comprising generalized slow spikes-waves, mental deficiency and early onset of multiple and different seizures types) is usually divided into symptomatic or criptogenetic group, based on the presence or absence of 
neurological abnormalities or specific causes [83,84]. Symptomatic cases present different causes such as hypoxic-ischemic encephalopathy, vascular demage, perinatal meningoencephalitides, tuberous sclerosis, Down's Syndrome, trauma, brain tumor and malformations [83]; in the $10-25 \%$ of the patients a previous history of WS is reported [85].

Usually the onset of LGS is about 8 years of age and occurrence rates peak between 3 and 5 years. Clinically the type of seizures are different depending on the phases of the syndrome; tonic seizures are the most frequent and peculiar type of seizures (tonic axial seizures, particularly during sleep), but are not necessarily present at the onset. Tonic refers to "a sustained increase in muscle contraction lasting a few seconds or minutes". The patients can present flexor movement of head and trunk with apnoea and brief cry associated with abduction of the limbs, which usually involves the arms; in others patients the tonic seizures might involve not only trunkal muscles, and we can observe global tonic attacks [86]. The second seizure mainly associated with LGS is atypical absence, characterized by a brief loss of consciousness. Atonic falls or drop attacks are hazardous and occur in $56 \%$ of patients who have slow spikewaves, but are not diagnostic of LGS [87].

At EEG the characteristic and peculiar abnormalities are burst of diffuse slow spike-waves at 2-2,5 c/s during wakefulness, or burst or fast waves and slow polyspikes and generalized fast activity at about $10 \mathrm{c} / \mathrm{s}$ during sleep; this latter EEG finding is almost pathognomonic for LGS.

Developmental delay increases with time and the patients loose cognitive and intellectual skills. The prognosis of these patients is very poor and often their epilepsy remains untreatable [85].

Old AEDs for LGS treatment include benzodiazepine (CLB, CZP, diazepam (DZP), LZP, NZP), PB, Primidone (PRM), PHT, VPA, GVG [77]. Benzodiazepine are still prescribed with the specific risk in LGS of precipitating tonic status epileptic (TSE) [88]. Though they can control tonic-clonic seizures, PB and PRM should be avoided due to cognitive and sedative side effects [89]. PTH can control tonic-clonic seizures and reduce tonic seizures in LGS, but it can aggravate atypical absences and myoclonic seizures [84]. More recent therapeutic options in LGS are FBM, LTG, TPM and RUF $[90,91]$. FBM was the first to be approved for adjunctive therapy in LGS and showed a significant effect on "major" seizures. Severe adverse effects appeared a few months after approval and so, since 1994, FBM was administered exclusively for LGS refractory to other AEDs.

Antiepileptic and other drugs used "off-label" in LGS are acetazolamide (AZM), allopurinol, bromide, flunarizine, pyridoxine, ZNS [92].
LGS can occur in association with a variety of specific malformation of cortical development where Mendelian inheritance may be observed [93]. The occurrence in siblings is extremely rare and has been reported in a family with bilateral frontoparietal polymicrogyria due to GPR56 mutations [94]. Recently Lawrence et al reported a novel DXC mutation in a family with three siblings affected by LGS and anterior pachygyria [95].

\section{Benign childhood epilepsy with centrotemporal spikes (BCECTS)}

Benign childhood epilepsy with centrotemporal spikes (BCECTS), or benign rolandic epilepsy (BRE), characteristically starts between 3 and 10 years of age, with a peak at 7 to 8 , and resolves by puberty [96].

BCECTS, are usually brief, unilateral, tonic, clonic, or tonic-clonic, convulsions involving the face, lips, tongue, pharyngeal, and laryngeal muscles, with speech arrest, saliva pooling and drooling without loss of consciousness. The seizures usually occur during sleep and are sometimes followed by secondary generalization. The most common inter-ictal EEG features are centro-temporal diphasic or triphasic sharps or spikes occasionally spreading to the homologous contra-lateral region. BCECTS usually is associated with "idiopathic" conditions but it has also been reported with brain lesions such as cortical dysplasia [97]. Few ictal EEG in cases of rolandic epilepsy have been recorded; in these ceses the seizures begin with fast rhythms and spikes in the rolandic area that is contralateral to the clinical seizures, with a progressive increase in amplitude and admixture of slow waves or polyspikes waves.

Although BCECTS is considered a benign form of childhood epilepsy that occurs in children who show normal mental development, recent researches support the view that children with BCECTS show deficient performance in various neuropsychological areas, without a definition of a uniform profile $[98,99]$.

On the other hand, the impact of epilepsy on cognitive function is complex, with many variables that can influence cognitive ability and interact, making it difficult to determine which factors contribute to the cognitive impairment [100]. In children with rolandic epilepsy, our group recently clearly indicate [98] an impairment in selectivity (impulsivity, focused attention, selective attention, aspects of divided attention) and in one measure of intensity (arousal) of attention whereas, the other measure of intensity of attention (vigilance) showed no impairment. Moreover, deficits of speechrelated abilities seemed to be independent of the effects of antiepileptic treatment and are reversible after remission of epilepsy [99].

A strong genetic susceptibility has been suggested in BCECTS [101,102]. Very recently, a genome-wide study 
demonstrated linkage of the centrotemporal sharp wave EEG trait to 11 p13 and several polymorphic markers in the ELP4 (Elongator Protein Complex 4) gene showed association with the BCECTS phenotype [103].

In contrast with most canonical forms of BCECTS, a rare syndrome combining the features of BCECTS and of speech and language disorders (rolandic epilepsy with speech dyspraxia, autosomal dominant: RESDAD) has shown monogenic inheritance [104]. Other families with monogenic inheritance of a syndrome with clinical features reminiscent, if not identical, to RESDAD and RESDX, have been described more recently [105]. Mutations in SRPX2 (Sushi-Repeat Protein, X-linked 2) cause rolandic epilepsy with speech impairment (RESDX syndrome) or with altered development of the speech cortex (bilateral perisylvian polymicrogyria) [106]. Comorbidity between BCECTS and altered development of speech motor control (also known as speech sound disorder) has also been further demonstrated in a recent case-control study [107]. Another BCECTS-associated genetic syndrome has been reported in a consanguineous family with rolandic epilepsy, paroxysmal exercise-induced dystonia, and writer's cramp. The syndrome is inherited as a recessive trait and linkage was found at 16p12-p11 [108], within the "infantile convulsions and choreoathetosis (ICCA)" critical region [109].

\section{Landau-Kleffner Syndrome}

Landau Kleffner (LKS) is a rare syndrome of unknown etiology (more common in the children between 5 and 7 years af age) which consists mainly of loss of language skills in children previously normal $[110,28]$. Language regression may occur suddenly or in a prolonged period and aphasia can be primarily receptive or expressive; probably the language disorder can be defined as a verbal auditory agnosia, that consists of a loss of verbal comprehension, which may be confused as a acquired deafness [111]. This aphasia is followed by gradual deterioration also in verbal production and, finally, mutism and failure to respond to non-verbal sounds [111]. Associated with language disorder the children with LKS in the majority of cases present different types of seizures, which include episodes of eye blinking or ocular deviation, head drop and minor automatisms with secondary generalization. In other cases, sizures are focal or tonicclonic generalized seizures, typical absences, partial complex and occasionally myoclonic seizures [112]. Early response to treatment and late outcome in LKS can be markedly different if the onset is in pre-linguistic phase (onset under the age of 3-4 years) and these children can be misdiagnosed for autistic due to impaired linguistic skills [113].
EEG shows bilateral temporal spikes or spikes waves, increasing during sleep. In these patients an awake EEG usually demonstrates normal background activity and focal epileptiform abnormalities especially on the temporal lobes; rarely awake EEG can be normal, making video-NPSG mandatory in these subjects. During the sleep EEG recording it is observed an activation and diffusion of the epileptic discharges, whereas the pattern of electrical status epilepticus during sleep (ESES or CSWS) may often be observed [111]. ESES picture is characterized by a continuous diffuse spike-waves during SS [114] (Figure 2) (see criteria definition for ESES in the next paragraph). ESES or CSWS presence is not mandatory to make diagnosis of LKS, although it is frequently associated [115].

Clinical seizures control in LKS is easy to obtain much more than ESES picture remission. Sleep EEG discharges in the majority of patients can persist months or years causing sometimes severe cognitive impairment, which can be transient, fluctuant or, rarely, irreversible with permanent cognitive deficits [100,111].

Among available AEDs, CBZ may cause a worsening of seizures and it should be avoided. The treatment of choice in LSK appears to be VPA as mono-therapy or in combination with a benzodiazepine [28]. Some authors suggest that steroids and ACTH should be considered the treatment of choice especially in early onset of disease [116] with improvement in speech abilities [117] and EEG anomalies recovery (Figure 3 ).

CLB, NZP, VPA, ESM and flunitrazepam have been used with benefits. PB, CBZ, PHT have been reported to be ineffective or harmful [28]. Language functions and EEG abnormalities would be influenced significantly by intravenous immunoglobulin administration [118].

The prognosis of LKS is benign in most cases, although the improvement of language depends on age of onset (pre and post-linguistic onset) of the disorder and the severity of the epileptic seizures. Early onset makes the prognosis poorer with persistent language difficulties even in the adult life [112].

There is familial association that suggests a genetic factor in the development of both the epileptic discharges on EEG and cognitive dysfunction but there is no direct evidence of genetic predisposition featuring in LKS etiology [119].

LKS, the continuous spike-and-waves during sleep syndrome (ESES or CSWSS), and the BCECTS are different entities that are considered as part of a single continuous spectrum of disorders. Recent reports on the involvement of the SRPX2 and ELP4 genes with possible roles in cell motility, migration, and adhesion have provided first insights into the complex molecular bases of childhood focal epilepsies [120]. 


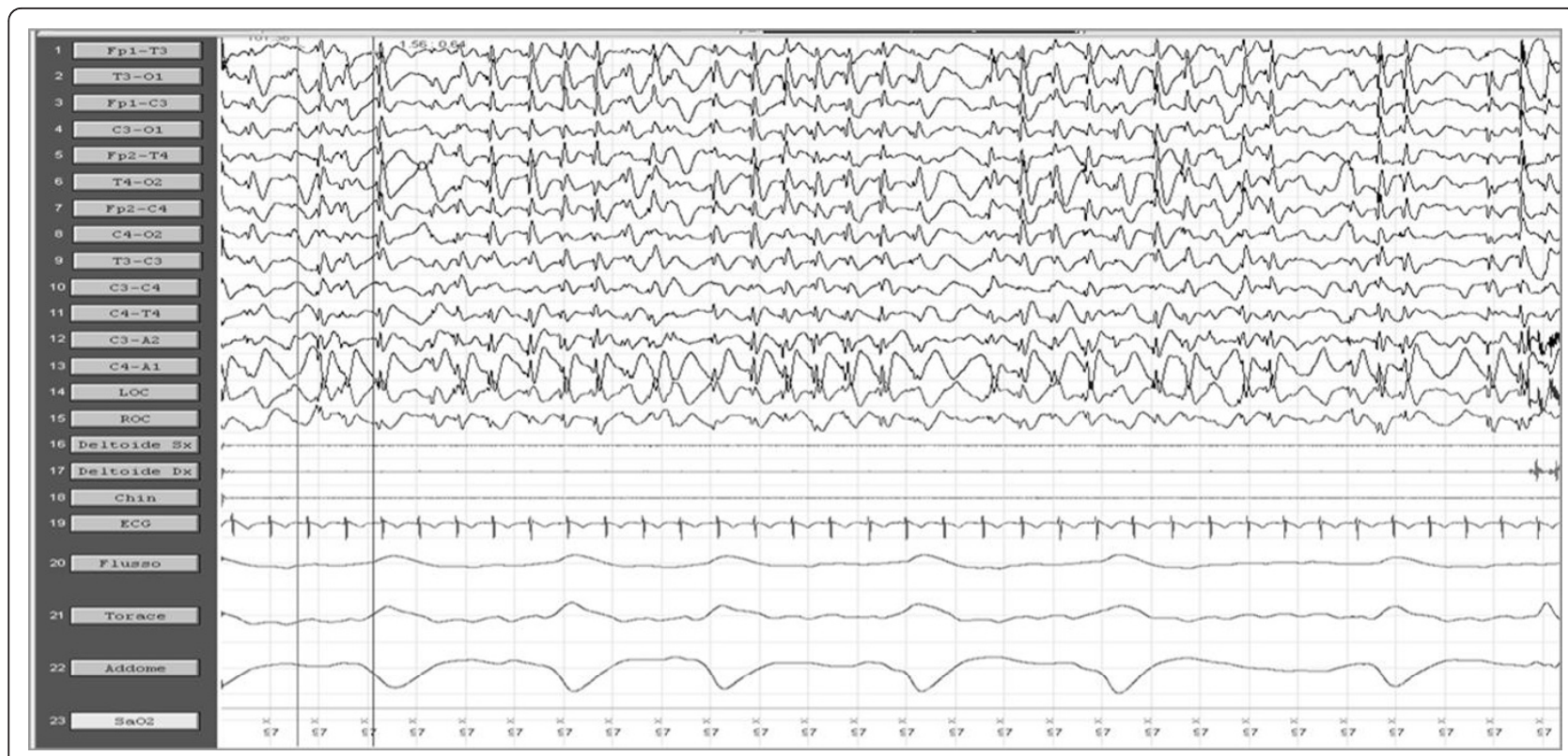

Figure $\mathbf{2}$ Neuropolisomnography recording, before oral hydrocortisone administration

\section{ESES or CSWSS}

ESES or CSWS is responsible for less than $1 \%$ of the age-dependent childhood EE, starting generally between the $5^{\text {th }}$ and $7^{\text {th }}$ year of life [121]. Even if these two terms are considered synonymous, ESES, firstly described by Tassinari [122], refers to the EEG pattern (continuous spike-wave complexes exclusively during non-REM sleep, with a spike-wave index accounting for at least 80-85\% of SS), while CSWS indicates both EEG features and clinical neuropsychological characteristics of this EE $[122,123]$. From a clinical point of view various seizures type are possible in CSWS affected patient: generalized tonic-clonic seizures during sleep, atypical absence, myoclonic and atonic seizures. Developmental delay and deterioration resulting in a IQ reduction, loss of speech, behavior and motor involvement (with ataxia, dystonia, dyspraxia) is often associated [121,123]. In CSWSS may be present a natural history consisting in three phases:

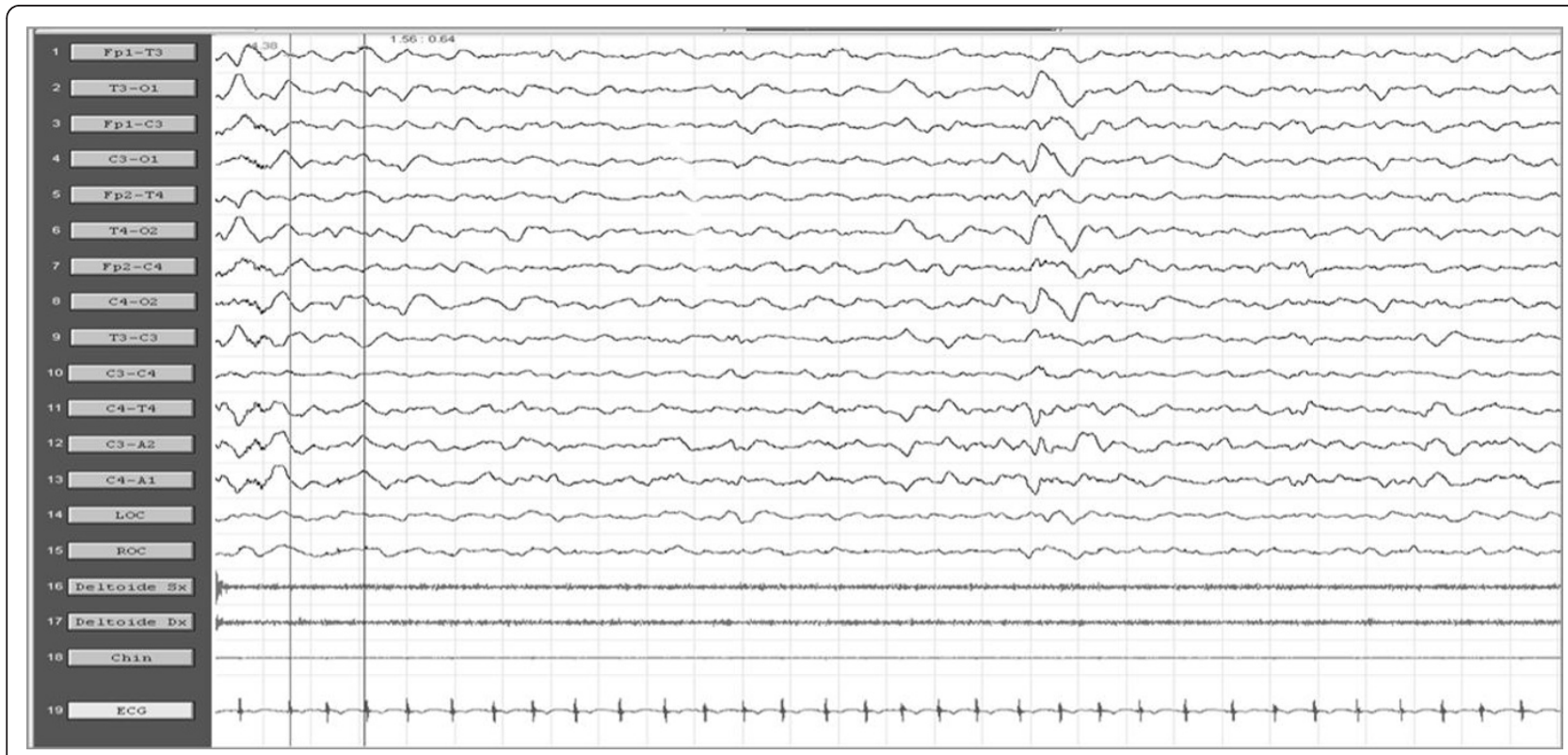

Figure 3 After oral hydrocortisone administration, a complete remission of ESES activity was observed. 
initial period with seizures and no developmental involvement (I); intermediate period with seizures, neuropsychological regression and ESES (II); final period with only neuropsychological deficits (III). However this evolution could be absent, and patients with CSWSS/ESES may present initially without seizures but "only" with developmental delay and/or behavior disturbance $[123,124]$. In these cases it could be useful to perform a video-NPSG investigation to deeper study the sleep EEG along the entire night [100].

A well-known partial epilepsy strongly related to ESES or CSWSS is the "Atypical Benign Partial Epilepsy of Infancy and Childhood" (ABPEI) also known as "Pseudo-Lennox Syndrome", firstly described by Aicard' e Chevrie [125]. It was often mistaken, in the past, for LGS because of the repeated atonic falls, absences and slow-wave activity at EEG. This form includes generalized seizures, atypical absences and atonic-astatic seizures. Axial tonic nocturnal seizures frequently observed in LGS are never observed in this type. ESES or CSWSS can be associated with ABPEI or even, in rare cases, with "Rolandic Epilepsy" [126].

Numerous AEDs have been used for the treatment of CSWSS, such as LTG, LEV, VPA, steroids, benzodiazepine; among the latter, high doses of DZP have been used with good results [121]. ESES or CSWSS pictures may be sometimes particularly refractory to AEDs and corticosteroid therapy (Figure 2 and 3) or AZM (12-15 $\mathrm{mg} / \mathrm{Kg} / \mathrm{die})$, in these cases, have shown sometimes good results [100].

ACTH or hydrocortisone are effective, but side-effects are well-known. High doses of benzodiazepine (LZP, NZP) are effective when given in by rapid venous infusion or rectally. The rectal administration of DZP $1 \mathrm{mg} /$ $\mathrm{kg}$ followed by an oral dose of $0.5 \mathrm{mg} / \mathrm{kg} /$ die for a period of 3 weeks gave positive results, with remissions lasting several months in 9/15 cases of ESES (60\%) and in one typical case of LKF syndrome [125].

There is little evidence to suggest a genetic cause. Only 1 pair of monozygotic twins with CSWS has been reported. A family history of seizures, including febrile convulsions, is found in up to $15 \%$ of children with CSWSS [127]. A recent report of two families characterized by coexistent BCECTS and cryptogenic epilepsy with ESES in first-degree relatives suggest a possible genetic basis [128].

\section{Late-onset childhood occipital epilepsy (Gastaut type)}

Gastaut type-idiopathic childhood occipital epilepsy (GICOE) or idiopathic childhood occipital epilepsy of late onset is a rare epileptic syndrome often with onset ranging from 3 to 15 years with a mean around 8 years of age. It is a pure form of idiopathic occipital epilepsy, included among the idiopathic focal epilepsies in childhood [1] with an uncertain long-term prognosis [129]. Seizure are purely occipital, frequent, brief and diurnal. They comprise simple partial seizures characterized by initial visual hallucinations (phosphenes and/or ictal blindness and illusions); ictal or postictal migraine headaches occur in half of the patients. Impairment of consciousness is rare unless associated with hemi-clonic or generalized convulsions [130]. Interictal EEG recordings reveal occipital spike and wave discharges that attenuate or disappear when the eyes are opened [131]. The prognosis is unclear, although remission occurs in $50-60 \%$ of patients within 2-4 years from onset. However, $40-50 \%$ of patients may continue to have visual seizures and infrequent secondary generalized tonic-clonic seizures, particularly if they have not been appropriately treated. Rarely, atypical evolutions to epilepsy with continuous spike-waves during slow wave sleep with cognitive deterioration have been reported [132].

Childhood occipital epilepsy-Gastaut type generally responds promptly to appropriate treatment with conventional AEDs, such as CBZ and VPA, with seizures usually remitting within 2-5 years. Verrotti et al. showed LEV as monohterapy to be effective and well tolerated [133].

The functional nature of this epilepsy syndrome was emphasized together with the presence of genetic predisposition in the affected patients. A possible autosomal dominant pattern for the EEG abnormalities with age dependent expression and variable penetrance of the seizure disorder has been proposed. Recent studies suggested an association between G-ICOE and idiopathic generalized epilepsies, suggesting that childhood absence epilepsy may have a closer genetic relationship to GICOE. There are reports about familial occurrence of GICOE [134].

\section{Jeavons Syndrome (Eyelid Myoclonia with Absences)}

Jeavons syndrome (JS) is one of the underreported epileptic syndromes characterized by eyelid myoclonia (EM), eye closure-induced seizures/electroencephalography (EEG) paroxysms, and photosensitivity (Figure 4 and 5). JS has been proposed as idiopathic generalized epilepsy (IGE) because of normal posterior dominant background activity and paroxysmal generalized ictal epileptiform discharges (EDs). The triad of manifestations are (1) eyelid myoclonia with and without absences; (2) eye closure-induced seizures and EEG paroxysms; and (3) photosensitivity [135].

Eyelid myoclonia, the hallmark of this syndrome, consists of marked jerking of the eyelids and often with jerky upward deviation of the eyeballs and the head (eyelid myoclonia without absences). This may be associated with or followed by mild impairment of consciousness (eyelid myoclonia with absences). The 


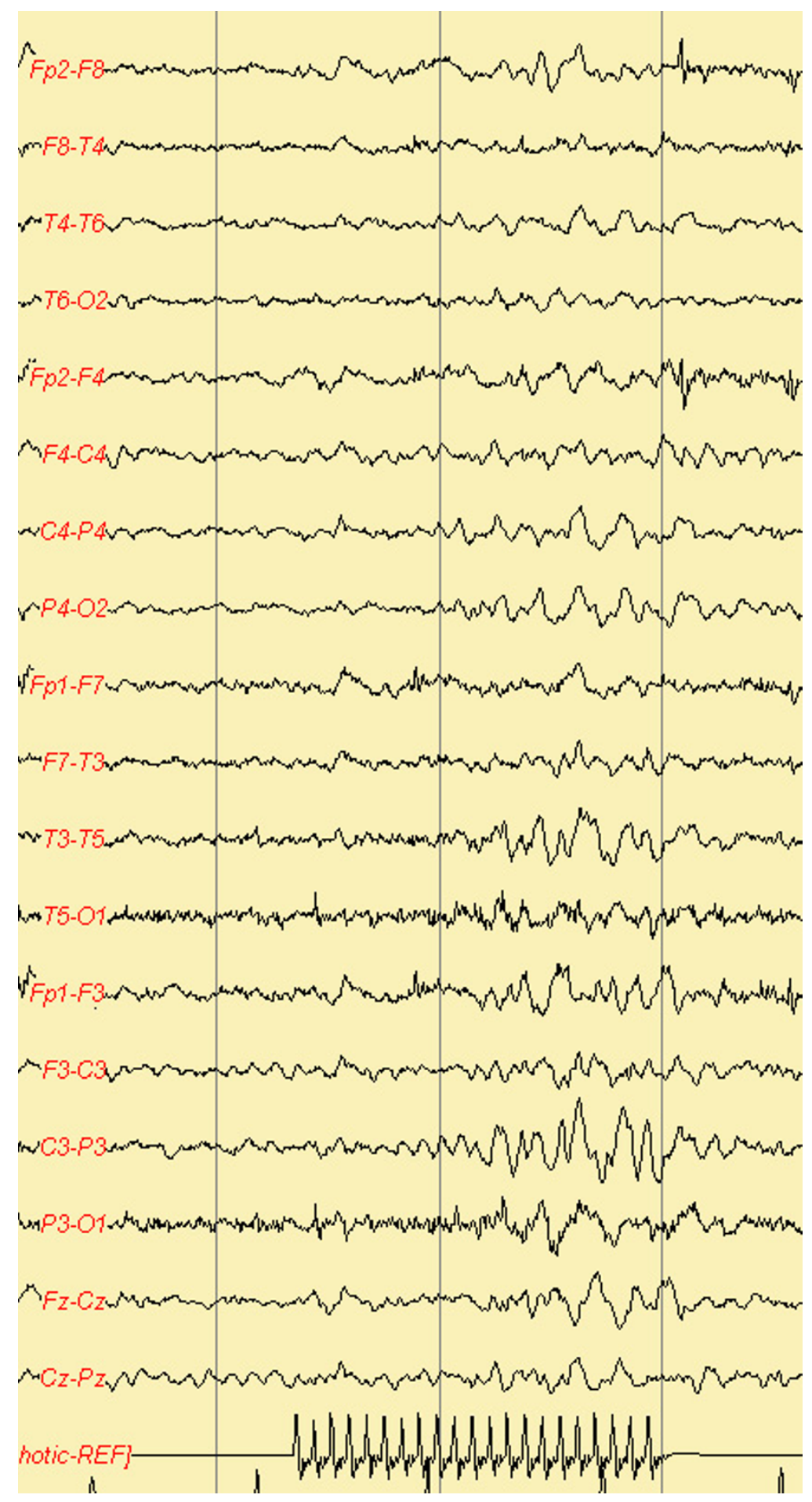

Figure 4 Focal Photosensitive Paroxysmal Response.

seizures are brief ( 3 to $6 \mathrm{sec}$ ) and occur mainly after eye closure and consistently many times per day. All patients are photosensitive. Generalized tonic-clonic seizures (GTCS), induced by lights or spontaneous, are probably inevitable in the long term and are particularly provoked by precipitating factors (sleep deprivation, alcohol) and inappropriate AEDs modifications. Typically, GTCS are sparse and avoidable. Myoclonic 


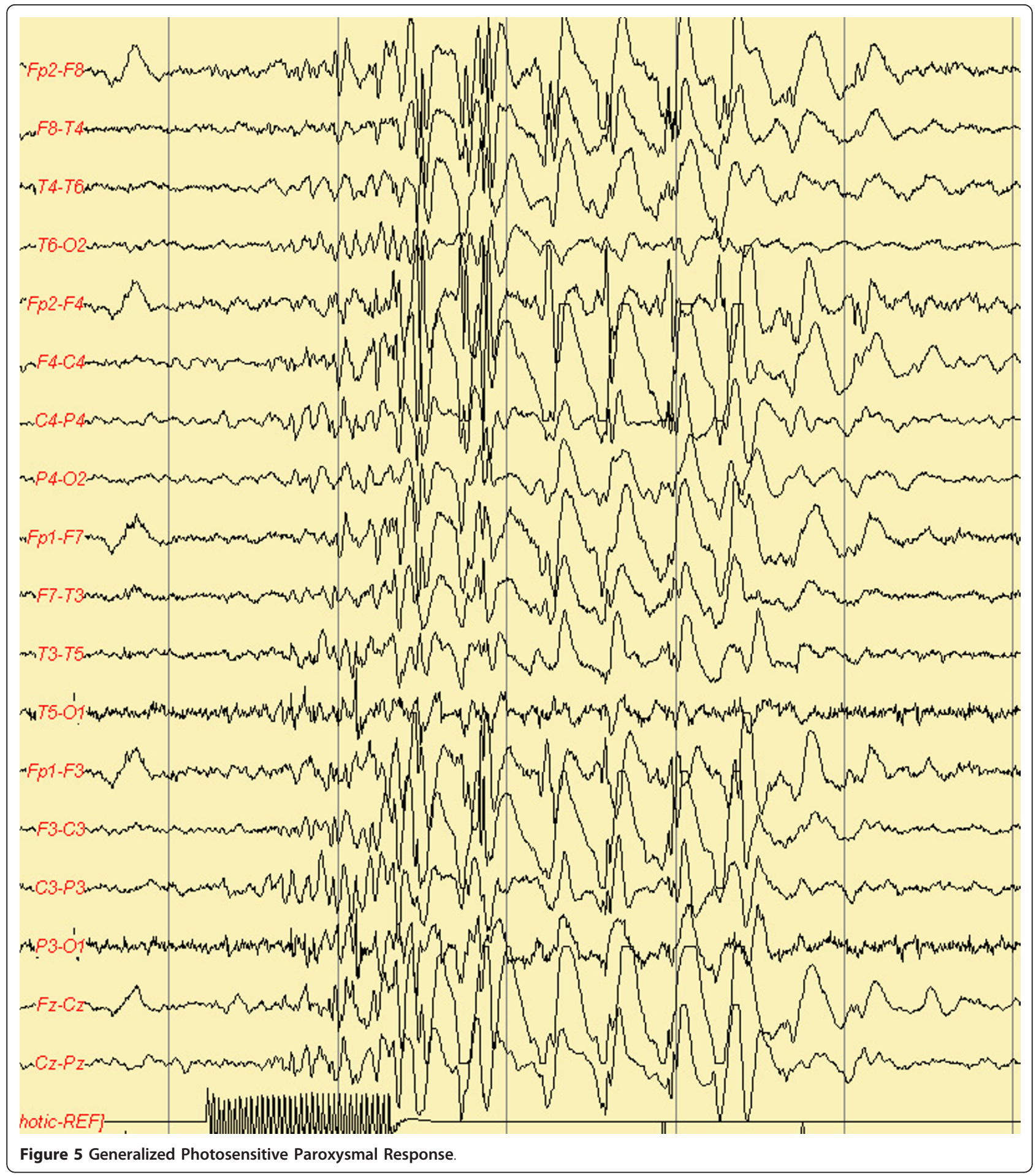

jerks of the limbs may occur but are infrequent and random. Eyelid myoclonic status epilepticus (1/5 of patients) consists of repetitive and discontinuous episodes of eyelid myoclonia with mild absence. VideoEEG is the most important procedure. It shows frequent and brief (2 to $3 \mathrm{sec}$ ) high-amplitude 3 to $6 \mathrm{~Hz}$ generalized spike and wave discharge of mainly polyspikes, which generally occur after eye closure. These are frequently associated with eyelid myoclonia. Photoparoxysmal responses occur in all untreated young patients. VPA, CNZ, ESM, and LEV are treatment options $[135,136]$. 


\section{Conclusions}

There are some ECS with onset in paediatric age which can be associated with psychomotor development and cognitive skills deterioration; to prevent neuropsychiatric impairment, an early recognition can allow us to properly manage diagnostic flow-charts and appropriate therapeutic options,. Sleep interictal EEG discharges (even without associated diurnal or nocturnal clinical seizures) are able to cause transitory or permanent cognitive impairment, particularly in children with high rate of inter-ictal spiking. Cognitive functions, mainly under frontal lobe control, seem to be particularly vulnerable to epileptic EEG activity during the period of brain development and maturation. In this respect, from a physiopathological point of view, the most intriguing issue is represented by the relationship between ESES and the pattern of neuropsychological and/or motor derangement. Moreover, it become easy to understand how important is to search for new AEDs which will be able to achieve a better control of both, the clinical seizures and interictal paroxysmal EEG abnormalities, particularly during sleep.

In other cases, such as in Panayiotopoulos Syndrome, to avoid over-treatments, it is also crucial to know that even numerous long lasting "autonomic status epilepticus" episodes, seem to be associated with normal cognitive development. Yet, new advances on clinical natural course and slight cognitive impairment sometimes associated with BCECTS must warn about possible cognitive impairment in these epileptic children previously considered not at all at risks.

Finally, the knowledge of specific electro-clinical syndrome will help epileptologists to make the right diagnostic and therapeutic decisions for treating our children.

\section{Author details \\ ${ }^{1}$ NESMOS Department, Chair of Pediatrics, Child Neurology, Faculty of Medicine and Psychology " "Sapienza" University, Via di Grottarossa, 1035- 1039, Rome,00189, Italy. 'Department of Paediatrics, University of Chieti, Ospedale policlinico SS. Annunziata, Via dei Vestini 5, 66100 Chieti, Italy.}

\section{Authors' contributions}

PP conceived of the study, and participated in its design, coordination and drafting/revising of the Review. AV, MCP, RC, FI, AF, FC and MPV participated in the design and drafting/revising of the review. All Authors read and approved the final manuscript

\section{Competing interests}

All Authors report nor disclosures nor conflicts of interests in publishing this review.

Received: 19 July 2011 Accepted: 19 December 2011

Published: 19 December 2011

\section{References}

1. Engel J: ILAE Commission Report. A Proposed Diagnostic Scheme for People with Epileptic Seizures and with Epilepsy: Report of the ILAE
Task Force on Classification and Terminology. Epilepsia 2001, 42(6):796-803.

2. Berg AT, Berkovic SF, Brodie MJ, Buchhalter J, Cross JH, van Emde Boas W, Engel J, French J, Glauser TA, Mathern GW, Moshé SL, Nordli D, Plouin P, Scheffer IE: Revised terminology and concepts for organization of seizures and epilepsies: report of the ILAE Commission on Classification and Terminology 2005-2009. Epilepsia , 4 2010, 51:676-685.

3. Ohtahara S, Ishida T, Oka E, Yamatogi Y, Inoue H, Kanda S: On the specific age dependent epileptic syndrome: the early-infantile epileptic encephalopathy with suppression-bursts. No To Hattatsu 1972, 8:270-280.

4. Ohtahara S, Yamatogi Y: Epileptic encephalopathy in early infancy with suppression bursts. J Clin Neurophysiol 2003, 20(6):398-407.

5. Parisi P, Spalice A, Nicita F, Papetti L, Ursitti F, Verrotti A, lannetti P, Villa MP: Epileptic encephalopathy of infancy and childhood: electro-clinica pictures and recent understandings. Curr Neuropharm 2010, 8(4):409-21.

6. Kitamura K, Yanazawa M, Sugiyama N, Miura H, lizuka-Kogo A, Kusaka M, Omichi K, Suzuki R, Kato-Fukui Y, Kamiirisa K, Matsuo M, Kamijo S, Kasahara M, Yoshioka H, Ogata T, Fukuda T, Kondo I, Kato M, Dobyns WB, Yokoyama M, Morohashi K: Mutation of ARX causes abnormal development of forebrain and testes in mice and Xlinkedlissencephaly with abnormal genitalia in humans. Nature Genet 2002, 32:359-369.

7. Poirier K, Van Esch H, Friocourt G, Saillour Y, Bahi N, Backer S, Souil E, Castelnau-Ptakhine L, Beldjord C, Francis F, Bienvenu T, Chelly J: Neuroanatomical distribution of ARX in brain and its localization in GABAergic neurons. Brain Res Mol Brain Res 2004, 122:35-46.

8. Kato M, Saitoh S, Kamei A, Shiraishi H, Ueda Y, Akasaka M, Tohyama J, Akasaka N, Hayasaka K: A longer polyalanine expansion mutation in the ARX gene causes early infantile epileptic encephalopathy with suppression-burst pattern (Ohtahara syndrome). Am J Hum Genet 2007, 81:361-6.

9. Bonneau $D$, Toutain $A$, Laquerrière $A$, Marret $S$, Saugier-Veber $P$, Barthez MA, Radi S, Biran-Mucignat V, Rodriguez D, Gélot A: X-linked lissencephaly with absent corpus callosum and ambiguous genitalia (XLAG): clinical, magnetic resonance imaging, and neuropathological findings. Ann Neurol 2002, 51:340-9.

10. Bhaskar K, Shareef MM, Sharm VM, Shetty AP, Ramamohan Y, Pant HC, Raju TR, Shetty KT: Co-purification and localization of Munc 18-1 (p67) and Cdk5 with neuronal cytoskeletal proteins. Neurochem Intern 2004, 44:35-44.

11. Weimer RM, Richmond JE, Davis WS, Hadwiger G, Nonet ML, Jorgensen EM: Defects in synaptic vescicle docking in munc-18 mutants. Nature Neurosci 2003, 6:1023-30.

12. Deprez L, Weckhuysen S, Holmgren P, Suls A, Van Dyck T, Goossens D, DelFavero J, Jansen A, Verhaert K, Lagae L, Jordanova A, Van Coster R, Yendle S, Berkovic SF, Scheffer I, Ceulemans B, De Jonghe P: Clinical spectrum of early-onset epileptic encephalopathies associated with STXBP1 mutations. Neurology 2010, 75:1159-65.

13. Hamdan FF, Piton A, Gauthier J, Lortie A, Dubeau F, Dobrzeniecka S, Spiegelman D, Noreau A, Pellerin S, Côté M, Henrion E, Fombonne E, Mottron L, Marineau C, Drapeau P, Lafrenière RG, Lacaille JC, Rouleau GA, Michaud JL: De novo STXBP1 mutations in mental retardation and non syndromic epilepsy. Ann Neurol 2002, 65:748-53.

14. Takusa Y, Ito M, Kobayashi A, Sejima H, Kishi K, Shiraishi H: Effect of the ketogenic diet for West syndrome into which early infantile epileptic encephalopathy with suppression-burst was evoked. No too Hattatsu 1995, 27:383-7.

15. Yoshikawa H, Ikeda S, Watanabe T: Liposteroid therapy in a case of early infantile epileptic encephalopathy with suppression-burst. No too Hattatsu 1998, 30:551-95.

16. Ohno M, Shimotsuji Y, Abe J, Shimada M, Tamiya H: Zonisamide treatment of early infantile epileptic encephalopathy. Pediatr Neurol 2000, 23:341-44.

17. Ozawa H, Kawada Y, Noma S, Sugai K: Oral high-dose phenobarbital therapy for early infantile epileptic encephalopathy. Pediatr Neurol 2002, 26:222-24

18. Krief $P$, Kan L, Maytal J: Efficacy of levetiracetam in children with epilepsy younger than 2 years of age. J Chil Neurol 2008, 23:582-4.

19. Cazorla MR, Verdù A, Montes C, Ayuga F: Early infantile epileptic encephalopathy with unusual favourable outcome. Brain Dev 2010, 32(8):673-6.

20. Hamiwka L, Duchowny M, Alfonso I, Liu E: Hemispherectomy in Early Infantile Epileptic Encephalopathy. J Child Neurol 2007, 22:41-44. 
21. Bellini G, Miceli F, Soldovieri MV, Miraglia del Giudice E, Pascotto A, Taglialatela M: Benign Familial Neonatal Seizures. In GeneReviews. Edited by: Pagon RA, Bird TC, Dolan CR, Stephens K. Seattle (WA): University of Washington, Seattle; 1993-2010.

22. Ronen GM, Rosales TO, Connolly M, Anderson VE, Leppert M: Seizure characteristics in chromosome 20 benign familial neonatal convulsions. Neurology 1993, 43:1355-60.

23. Coppola G, Castaldo P, Miraglia del Giudice E, Bellini G, Galasso F, Soldovieri MV, Anzalone L, Sferro C, Annunziato L, Pascotto A, Taglialatela M: A novel KCNQ2 K+ channel mutation in benign neonatal convulsions and centrotemporal spikes. Neurology 2003, 61:131-4.

24. Castaldo P, Miraglia del Giudice E, Coppola G, Pascotto A, Annunziato L, Taglialatela M: Benign Familial Neonatal Convulsions Caused by Altered Gating of KCNQ2/KCNQ3 Potassium Channels. J Neurosci 2002, 22:RC199.

25. Porter RJ, Partito A, Sachdeo R, Noria V, Alves WM: Randomized, multicenter, dose-ranging trial of retigabine for partial-onset seizures. Neurology 2007, 68:1197-204.

26. Liao Y, Deprez L, Maljevic S, Pitsch J, Claes L, Hristova D, Jordanova A, AlaMello S, Bellan-Koch A, Blazevic D, Schubert S, Thomas EA, Petrou S, Becker AJ, De Jonghe P, Lerche H: Molecular correlates of age-dependent seizures in an inherited neonatal-infantile epilepsy. Brain 2010, 133(Pt 5):1403-14.

27. Striano P, Bordo L, Lispi ML, Specchio N, Minetti C, Vigevano F, Zara F: A novel SCN2A mutation in family with benign familial infantile seizures. Epilepsia 2006, 47(1):218-20

28. Dulac O: Epileptic Encephalopathies. Epilepsia 2001, 42(Suppl 3):23-26.

29. Hancock E, Osborne JP, Milnerc P: The treatment of West syndrome: a Cochrane review of the literature to December 2000. Brain Dev 2001, 23:624-34.

30. Mackay MT, Weiss SK, Adams-Webber T, Ashwal S, Stephens D, BallabanGill K, Baram TZ, Duchowny M, Hirtz D, Pellock JM, Shields WD, Shinnar S, Wyllie E, Snead OC, American Academy of Neurology, Child Neurology Society: Practice Parameter: Medical Treatment of Infantile Spasms: Report of the American Academy of Neurology and the Child Neurology Society. Neurology, 10 2004, 62:1668-81.

31. Strømme $P$, Mangelsdorf ME, Shaw MA, Lower KM, Lewis SM, Bruyere $H_{\text {, }}$ Lütcherath V, Gedeon AK, Wallace RH, Scheffer IE, Turner G, Partington M, Frints SG, Fryns JP, Sutherland GR, Mulley JC, Gécz J: Mutations in the human ortholog of Aristaless cause X-linked mental retardation and epilepsy. Nat Genet 2002, 30:441-45.

32. Weaving LS, Christodoulou J, Williamson SL, Friend KL, McKenzie OL, Archer H, Evans J, Clarke A, Pelka GJ, Tam PP, Watson C, Lahooti H, Ellaway CJ, Bennetts B, Leonard H, Gécz J: Mutations of CDKL5 cause a severe neurodevelopmental disorder with infantile spasms and mental retardation. Am J Hum Genet 2004, 75:1079-93.

33. Kato M, Das S, Petras K, Sawaishi Y, Dobyns WB: Polyalanine expansion of ARX associated with cryptogenic West syndrome. Neurology 2003, 61:267-76

34. Otsuka M, Oguni H, Liang JS, Ikeda H, Imai K, Hirasawa K, Imai K, Tachikawa E, Shimojima K, Osawa M, Yamamoto T: STXBPI mutation cause non only Ohtahara sindrome but also West sindrome- results of Japanese cohort study. Epilepsia 2010, 51(12):2449-52.

35. Balasubramanian M, Smith K, Mordekar SR, Parker MJ: Clinical report: An interstitial deletion of $16 \mathrm{p} 13.11$ detected by array CGH in a patient with infantile spasms. Eur J Med Genet 2011, 54(3):314-8.

36. Gumus $H$, Kumandas S, Per H: Levetiracetam monotherapy in newly diagnosed cryptogenic West Syndrome. Pediatr Neurol 2007, 37(5):350-3.

37. Suzuki Y: Zonisamide in West syndrome. Brain Dev 2001, 23:658-61.

38. Ohtahara S, Yamatogi Y: Ohtahara syndrome: With special reference to its developmental aspects for differentiating from early myoclonic encephalopathy. Epilepsy Res 2006, , 70S: S58-S67.

39. Guerrini R: Epilepsy in children. Lancet 2006, 367(9509):499-524.

40. Fejerman N, Cersosimo R, Caraballo R, Grippo J, Corral S, Martino RH, Martino G, Aldao M, Caccia P, Retamero M, Macat MC, Di Blasi MA, Adi J: Vigabatrin as a first choice drug in the treatment of west syndrome. $J$ Child Neurol 2000, 15(3):161-5.

41. Mikati AA, Lepejian GA, Holmes GL: Medical treatement of patients with infantile spasms. Clin Neuropharm 2002, 25(2):61-70.

42. Parisi $P$, Bombardieri $R$, Curatolo $P$ : Current role of Vigabatrin in infantile spasms. Eur J Paediatr Neurol 2007, 11:331-336.
43. Willmore LJ, Abelson MB, Ben-Menachem E, Pellock JM, Shields DW: Vigabatrin: 2008 Update. Epilepsia 2009, 50(2):163-73.

44. Wolff M, Casse-Perrot C, Dravet C: Severe myoclonic epilepsy of infants (Dravet syndrome): natural history and neuropsychological findings. Epilepsia 2006, 47(suppl 2):45-48.

45. Fujiwara T, Sugawara T, Mazaki-Miyazaki E, Takahashi Y, Fukushima K, Watanabe M, Hara K, Morikawa T, Yagi K, Yamakawa K, Inoue Y: Mutations of sodium channel alpha subunit type 1 [SCN1A] in intractable childhood epilepsies with frequent generalized tonic-clonic seizures. Brain 2003, 126(pt 3):531-46.

46. Fukuma G, Oguni H, Shirasaka Y, Watanabe K, Miyajima T, Yasumoto S, Ohfu M, Inoue T, Watanachai A, Kira R, Matsuo M, Muranaka H, Sofue F, Zhang B, Kaneko S, Mitsudome A, Hirose S: Mutations of neuronal voltage-gated $\mathrm{Na}+$ channel alpha 1 subunit gene SCN1A in core severe myoclonic epilepsy in infancy (SMEI) and in borderline SMEI (SMEB). Epilepsia 2004, 45:140-48.

47. Stafstrom CE: Severe epilepsy syndromes of early childhood: the link between genetics and pathophysiology with a focus on SCN1A mutations. J Child Neurol 2009, 24(Suppl):15S-23S.

48. Harkin LA, McMahon JM, Iona X, Dibbens L, Pelekanos JT, Zuberi SM, Sadleir LG, Andermann E, Gill D, Farrell K, Connolly M, Stanley T, Harbord M, Andermann F, Wang J, Batish SD, Jones JG, Seltzer WK, Gardner A, Infantile Epileptic Encephalopathy Referral Consortium, Sutherland G, Berkovic SF, Mulley JC, Scheffer IE: The spectrum of SCN1A-related infantile epileptic encephalopathies. Brain 2007, 130(pt3):843-52.

49. Claes LR, Deprez L, Suls A, Baets J, Smets K, Van Dyck T, Deconinck T, Jordanova A, De Jonghe P: The SCN1A variant database: a novel research and diagnostic tool. Hum Mut 2009, 30:E904-E920.

50. Ogiwara I, Ito K, Sawaishi Y, Osaka H, Mazaki E, Inoue I, Montal M, Hashikawa T, Shike T, Fujiwara T, Inoue Y, Kaneda M, Yamakawa K: De novo mutations of voltage-gated sodium channel alphall gene SCN2A in intractable epilepsies. Neurology 2009, 73(13):1046-53.

51. Shi X, Yasumoto S, Nakagawa E, Fukasawa T, Uchiya S, Hirose S: Missense mutation of the sodium channel gene SCN2A causes Dravet syndrome. Brain Dev 2009, 31(10):758-62.

52. Baulac S, Huberfeld G, Gourfinkel-An I, Mitropoulou G, Beranger A Prud'homme JF, Baulac M, Brice A, Bruzzone R, LeGuern E: First genetic evidence of $G A B A(A)$ receptor dysfunction in epilepsy: a mutation in the gamma2-subunit gene. Nat Genet 2001, 28:46-8.

53. Wallace RH, Scheffer IE, Parasivam G, Barnett S, Wallace GB, Sutherland GR, Berkovic SF, Mulley JC: Generalized epilepsy with febrile seizures plus: mutation of the sodium channel subunit SCN1B. Neurology 2002, 58:1426-29.

54. Korff C, Laux L, Kelley K, Goldstein J, Koh S, Nordli D Jr: Dravet syndrome (severe myoclonic epilepsy in infancy): a retrospective study of 16 patients. J Child Neurol 2007, 22:185-94.

55. Caraballo RH, Fejerman N: Dravet syndrome: a study of 53 patients. Epilepsy Res 2006, 70(Suppl1):S231-8.

56. Chiron C: Current therapeutic procedures in Dravet syndrome. Dev Med Child Neurol 2011, 53(Suppl 2):16-8.

57. Chiron C, Marchand MC, Tran A, Rey E, d'Athis P, Vincent J, Dulac O, Pons G: Stiripentol in sevee myoclonic epilepsy in infancy: a randomised placebo-controlled syndrome dedicated trial. STICLO study group Lancet 2000, 356:1638-42.

58. Guerrini R, Dravet C, Genton P, Belmonte A, Kaminska A, Dulac O: Lamotrigine and seizure aggravation in severe myoclonic epilepsy. Epilepsia 1998, 39(5):508-12

59. Striano P, Striano S, Minetti C, Zara F: Refractory, life-threatening status epilepticus in a 3-year-old girl. Lancet Neurol 2008, 7(3):278-84

60. Verrotti A, Olivieri C, Agostinelli S, Coppola G, Parisi P, Grosso S, Spalice A, Zamponi N, Franzoni E, lannetti P, Chiarelli F, Curatolo P: Long term outcome in children affected by absence epilepsy with onset before the age of three years. Epilepsy Behav 2011, 20:366-9.

61. Verrotti A, Agostinelli S, Olivieri C, Chiarelli F, Curatolo P: Early-onset pure absence epilepsy: a distinct epileptic syndrome. Acta Paediatr 2011, 100(5):647-50.

62. Wallace RH, Marini C, Petrou S, Harkin LA, Bowser DN, Panchal RG, Williams DA, Sutherland GR, Mulley JC, Scheffer IE, Berkovic SF: Mutant $\mathrm{GABA}(\mathrm{A})$ receptor gamma2-subunit in childhood absence epilepsy and febrile seizures. Nat Genet 2001, 28(1):49-52. 
63. Marini C, Harkin LA, Wallace RH, Mulley JC, Scheffer IE, Berkovic SF: Childhood absence epilepsy and febrile seizures: a family with a GABA [A] receptor mutation. Brain 2003, 126:230-40.

64. Audenaert D, Claes L, Ceulemans B, Löfgren A, Van Broeckhoven C, De Jonghe P: A deletion in SCN1B is associated with febrile seizures and early-onset absence epilepsy. Neurology 2003, 61(6):854-56.

65. Suls A, Mullen SA, Weber YG, Verhaert K, Ceulemans B, Guerrini R, Wuttke TV, Salvo-Vargas A, Deprez L, Claes LR, Jordanova A, Berkovic SF, Lerche $H$, De Jonghe P, Scheffer IE: Early-Onset Absence Epilepsy Caused by Mutations in the Glucose Transporter GLUT. Ann Neurol 2009, 66(3):415-19.

66. Seidner G, Alvarez MG, Yeh Jl, O'Driscoll KR, Klepper J, Stump TS, Wang D, Spinner NB, Birnbaum MJ, De Vivo DC: GLUT-1 deficiency syndrome caused by haploinsufficiency of the blood-brain barrier hexose carrier. Nat Genet 1998, 18(2):188-91.

67. Suls A, Dedeken P, Goffin K, Van Esch H, Dupont P, Cassiman D, Kempfle J, Wuttke TV, Weber Y, Lerche H, Afawi Z, Vandenberghe W, Korczyn AD, Berkovic SF, Ekstein D, Kivity S, Ryvlin P, Claes LR, Deprez L, Maljevic S, Vargas A, Van Dyck T, Goossens D, Del-Favero J, Van Laere K, De Jonghe P, Van Paesschen W: Paroxysmal exercise-induced dyskinesia and epilepsy is due to mutations in SLC2A1, encoding the glucose transporter GLUT1. Brain 2008, 131:1831-44.

68. Mullen SA, Suls A, De Jonghe P, Berkovic SF, Scheffer IE: Absence epilepsies with widely variable onset are a key feature of familial GLUT1 deficiency. Neurology 2010, 75(5):432-40.

69. Fernandez-Torre JL, Herranz JL, Martinez-Martinez M, Maestro I, Arteaga R, Barrasa J: Early onset absence epilepsy: clinical features in three children. Brain Dev 2006, 28:311-4.

70. Covanis A: EEG and clinical correlates of early onset typical absences (age less than three years). Epilepsia 1998, 39(Suppl 2):92.

71. Covanis A: Panayiotopoulos syndrome: a benign childhood autonomic epilepsy frequently imitating encephalitis, syncope, migraine, sleep disorder, or gastroenteritis. Pediatrics 2006, 118(4):e1237-43.

72. Parisi P, Ferri R, Pagani J, Cecili M, Montemitro E, Villa MP: Ictal videopolysomnography and EEG spectral analysis in a child with severe Panayiotopoulos syndrome. Epileptic Disord 2005, 7(4):333-9.

73. Panayiotopoulos CP: Benign nocturnal childhood occipital epilepsy: a new syndrome with nocturnal seizures, tonic deviation of the eyes, and vomiting. J Child Neurol 1989, 4(1):43-9.

74. Koutroumanidis M, Rowlinson S, Sanders S: Recurrent autonomic status epilepticus in Panayiotopoulos syndrome: video/EEG studies. Epilepsy Behav 2005, 7(3):543-7.

75. Ferrie CD, Caraballo R, Covanis A, Demirbilek V, Dervent A, Fejerman N, Fusco L, Grünewald RA, Kanazawa O, Koutroumanidis M, Lada C, Livingston JH, Nicotra A, Oguni $H$, Martinovic Z, Nordli DR Jr, Parisi P, Scott RC, Specchio N, Verrotti A, Vigevano F, Walker MC, Watanabe K, Yoshinaga H, Panayiotopoulos CP: Autonomic status epilepticus in Panayiotopoulos syndrome and other childhood and adult epilepsies: a consensus view. Epilepsia 2007, 48(6):1165-72.

76. Specchio N, Trivisano M, Claps D, Battaglia D, Fusco L, Vigevano F: Documentation of autonomic seizures and autonomic status epilepticus with ictal EEG in Panayiotopoulos syndrome. Epilepsy Behav 2010, 19(3):383-93.

77. Kanazawa O, Tohyama J, Akasaka N, Kamimura T: A magnetoencephalographic study of patients with Panayiotopoulos syndrome. Epilepsia 2005, 46(7):1106-13.

78. Verrotti A, Salladini C, Trotta D, di Corcia G, Chiarelli F: Ictal cardiorespiratory arrest in Panayiotopoulos syndrome. Neurology 2005, 64(10):1816-7.

79. Specchio N, Trivisano M, Di Ciommo V, Cappelletti S, Masciarelli G, Volkov J, Fusco L, Vigevano F: Panayiotopoulos syndrome: a clinical, EEG, and neuropsychological study of 93 consecutive patients. Epilepsia 2010, 51(10):2098-107.

80. Livingston $\mathrm{JH}$, Cross $\mathrm{JH}$, Mclellan A, Birch R, Zuberi SM: A novel inherited mutation in the voltage sensor region of SCN1A is associated with Panayiotopoulos syndrome in siblings and generalized epilepsy with febrile seizures plus. J Child Neurol 2009, 24(4):503-8.

81. Martín Del Valle F, Díaz Negrillo A, Ares Mateos G, Sanz Santaeufemia FJ, Del Rosal Rabes T, González-Valcárcel Sánchez-Puelles FJ: Panayiotopoulos syndrome: probable genetic origin, but not in SCN1A. Eur J Paediatr Neurol 2011, 15(2):155-7.
82. Garcia C, Rubio G: Efficacy and safety of levetiracetam in the treatment of Panayiotopoulos syndrome. Epilepsy Res 2009, 85(2-3):318-20.

83. Markand ON: Lennox-Gastaut Syndrome (childhood epileptic encephalopathy). J Clin Neurophysiol 2003, 20(6):426-41.

84. Sarzgar M, Bourgeois BF: Aggravation of epilepsy by antiepileptic drugs. Pediatric Neurology 2005, 33:227-34.

85. Arzimanoglou A, French J, Blume WT, Cross JH, Ernst JP, Feucht M, Genton P, Guerrini R, Kluger G, Pellock JM, Perucca E, Wheless JW: LennoxGastaut syndrome: a consensus approach on diagnosis, assessment, management, and trial methodology. Lancet Neurol 2009, 8:82-93.

86. Abu Saleh T, Stephen L: Lennox gastaut syndrome, review of the literature and a case report. Head Face Med 2008, 9:4-9.

87. Chevrie JJ, Aicardi J: Childhood epileptic encephalopathy with slow spike-wave. A statistical study of 80 cases. Epilepsia 1972, 13:259-71.

88. Dimario FJ, Clancy RR: Paradoxical precipitation of tonic seizures by lorazepam in child with atypical absence seizures. Pediatr Neurol 1988, 4:249-51.

89. Delanty N, French J: Treatment of Lennox-Gastaut syndrome: current recommendations. CNS Drugs 1998, 10:181-87.

90. Dulac O, Kaminska A: Use of lamotrigine in Lennox-Gastaut and related epilepsy syndromes. J Child Neurol 1997, 12(suppl 1):S23-28.

91. Van Rijckevorsel K: Treatment of Lennox-Gastaut syndrome: overview and recent findings. Neuropsychiatr Dis Treat 2008, 4(6):1001-1019.

92. Coppola G, Verrotti A, Ammendola E, Operto FF, Corte RD, Signoriello G, Pascotto A: Ketogenic diet for the treatment of catastrophic epileptic encephalopathies in childhood. Eur J Paediatr Neurol 2010, 14(3):229-34.

93. Guerrini R, Houlthausen H, Parmeggiani L, Parrini E, Chiron C: Epilepsy and malformations of the cerebral cortex. In Epileptic syndrome in infancy, childhood adolescence.. 4 edition. Edited by: Roger J, Bureau M, Dravet C, Genton P, Tassinari CA, Wolf P. Jhon Libbey Eurotext, Montrouge; 2005:493-518.

94. Parrini E, Ferrari AR, Dorn T, Walsh CA, Guerrini R: Bilateral frontoparietal polymicrogyria, Lennox-Gastaut sindrome, and GPR56 gene mutation. Epilepsia 2009, 50:1344-2353.

95. Lawrence KM, Mei Davide, Newton MR, Leventer RJ, Guerrini R, Berkovic SF: Familial Lennox-Gastaut syndrome in male siblings with a novel DCX mutation and anterior pachygyria. Epilepsia 2010, 51(9):1902-05.

96. Fejerman N: Benign childhood epilepsy with centrotemporal spikes. In Epilepsy: a comprehensive textbook.. 2 edition. Edited by: Fejerman N, Caraballo RH. Philadelphia: Lippincott Williams 2008:.

97. Iannetti P, Raucci U, Basile LA, Spalice A, Parisi P, Fariello G, Imperato C: Benign epilepsy of childhood with centrotemporal spikes and unilateral developmental opercular dysplasia. Childs Nerv Syst 1994, 10(4):264-9.

98. Cerminara C, D'Agati E, Lange KW, Kaunzinger I, Tucha O, Parisi P, Spalice A, Curatolo P: Benign childhood epilepsy with centrotemporal spikes and the multicomponent model of attention: a matched control study. Epilepsy Behav 2010, 19(1):69-77.

99. Verrotti A, D'Egidio C, Agostinelli S, Parisi P, Chiarelli F, Coppola G Cognitive and linguistic abnormalities in benign childhood epilepsy with centrotemporal spikes. Acta Paediatr 2011, 100(5):768-72.

100. Parisi P, Bruni O, Pia Villa M, Verrotti A, Miano S, Luchetti A, Curatolo P: The relationship between sleep and epilepsy: the effect on cognitive functioning in children. Dev Med Child Neurol 2010, 52(9):805-10.

101. Vadlamudi L, Harvey AS, Connellan MM, Milne RL, Hopper JL, Scheffer IE, Berkovic SF: Is benign rolandic epilepsy genetically determined? Ann Neurol 2004, 56(1):129-32.

102. Bali B, Kugler SL, Pal DK: Genetic influence on rolandic epilepsy. Ann Neurol 2005, 57(3):464-5.

103. Strug L, Clarke T, Chiang T, Chien M, Baskurt Z, Li W, Dorfman R, Bali B, Wirrell E, Kugler SL, Mandelbaum DE, Wolf SM, McGoldrick P, Hardison H, Novotny EJ, Ju J, Greenberg DA, Russo JJ, Pal DK: Centrotemporal sharp wave EEG trait in rolandic epilepsy maps to Elongator Protein Complex 4 (ELP4). Eur J Hum Genet 2009, 17(9):1171-81.

104. Scheffer IE, Jones L, Pozzebon M, Howell RA, Saling MM, Berkovic SF: Autosomal dominant rolandic epilepsy and speech dyspraxia: a new syndrome with anticipation. Ann Neurol 1995, 38(4):633-42.

105. Kugler SL, Bali B, Lieberman P, Strug L, Gagnon B, Murphy PL, Clarke T, Greenberg DA, Pal DK: An autosomal dominant genetically heterogeneous variant of rolandic epilepsy and speech disorder. Epilepsia 2008, 49(6):1086-90. 
106. Royer-Zemmour B, Ponsole-Lenfant M, Gara H, Roll P, Lévêque C, Massacrier A, Ferracci G, Cillario J, Robaglia-Schlupp A, Vincentelli R, Cau P, Szepetowski P: Epileptic and developmental disorders of the speech cortex: ligand/receptor interaction of wild-type and mutant SRPX2 with the plasminogen activator receptor UPAR. Hum Mol Genet 2008, 17(23):3617-30.

107. Clarke T, Strug LJ, Murphy PL, Bali B, Carvalho J, Foster S, et al: High risk of reading disability and speech sound disorder in rolandic epilepsy families: case-control study. Epilepsia 2007, 48(12):2258-65.

108. Guerrini R, Bonanni P, Nardocci N, Parmeggiani L, Piccirilli M, De Fusco M, Aridon P, Ballabio A, Carrozzo R, Casari G: Autosomal recessive rolandic epilepsy with paroxysmal exercise-induced dystonia and writer's cramp: delineation of the syndrome and gene mapping to chromosome 16p1211.2. Ann Neurol 1999, 45(3):344-52.

109. Rochette J, Roll P, Szepetowski P: Genetics of infantile seizures with paroxysmal dyskinesia: the infantile convulsions and choreoathetosis [ICCA] and ICCA-related syndromes. J Med Genet 2008, 45(12):773-9.

110. Shield DW: Catastrophic epilepsy in childhood. Epilepsia 2000, 41(suppl 2): S2-S6.

111. Smith MC, Hoeppner TJ: Epileptic encephalopathy of late childhood. Landau-Kleffner syndrome and the syndrome of continuous spikes and waves during slow-waves sleep. J Clin Neurophysiol 2003, 20(6):462-72.

112. Duran MHC, Guimaraes CA, Medeiros LL, Guerreiro MM: Landau-Kleffner syndrome: long-term follow-up. Brain Dev 2009, 31:58-63.

113. Deonna T, Roulet E: Autistic spectrum disorder: evaluating a possible contributing or causal role of epilepsy. Epilesia 2006, 47(Suppl 2):79-82.

114. Tsao CY: Current trends in the treatment of infantile spasms. Neuropsychiatr Dis Treat 2009, 5:289-99.

115. Yamatogi Y, Ohtahara S: Multiple independent spike foci and epilepsy, with special reference to a new epileptic syndrome of "severe epilepsy with multiple independent spike foci". Epilepsy Res 2006, 70(Suppl 1): S96-104.

116. Gallagher S, Weiss S, Oram Cardy J, Humphries T, Harman KE, Menascu S: Efficacy of very high dose steroid treatment in a case of Landau-Kleffner syndrome. Dev Med Child Neurol 2006, 48(9):766-9.

117. Lerman P, Lerman-Sagie T, Kivity S: Effect of early corticosteroid therapy for Landau-Kleffner syndrome: case report. Dev Med Child Neurol 1991, 33:257-33.

118. Arts WF, Aarsen FK, Scheltens-de Boer M, Catsman-Berrevoets CE: LandauKleffner syndrome and CSWS syndrome: treatment with intravenous immunoglobulins. Epilepsia 2009, 50(Suppl 7):55-8.

119. Hirsch E, Valenti MP, Rudolf G, Seegmuller C, de Saint Martin A, Maquet $P$, Wioland N, Metz-Lutz MN, Marescaux C, Arzimanoglou A: Landau-Kleffner syndrome is not an eponymic badge of ignorance. Epilepsy Res 2006, 70S: S239-S247.

120. Rudolf G, Valenti MP, Hirsch E, Szepetowski P: From rolandic epilepsy to continuous spike-and-waves during sleep and Landau-Kleffner syndromes: insights into possible genetic factors. Epilepsia 2009, 50(Suppl 7):25-8.

121. MacAllister WS, Schaffer SG: Neuropsychological Deficits in Childhood Epilepsy Syndromes. Neuropsychol Rev 2007, 17:427-44.

122. Tassinari CA, Daniele O, Gambarelli F, Bureau-Paillas M, Robaglia L, Cicirata F: Excessive 7-14-sec positive spikes during REM sleep in monozygotic non-epileptic twins with speech retardation. Rev Electroencephalogr Neurophysiol Clin 1977, 7(2):192-93.

123. Holmes GL, Lenck-Santini PP: Role of interictal epileptiform abnormalities in cognitive impairment. Epilepsy \& Behav 2006, 8:504-15.

124. Hirsch E, Valenti MP, Rudolf $G$, Seegmuller $C$, de Saint Martin A, Maquet $P$, Wioland N, Metz-Lutz MN, Marescaux C, Arzimanoglou A: Impact of early hemispherotomy in a case of Ohtahara syndrome with left parietooccipital megalencephaly. Seizure 2005, 14(6):439-42.

125. Aicardi J, Chevrie JJ: Atypical benign partial epilepsy of childhood. Dev Med Child Neurol 1987, 24(3):281-92.

126. Fejerman N, Caraballo R, Tenembaum SN: Atypical evolutions of benign localization-related epilepsies in children: are they predictable? Epilepsia 2000, 41(4):380-90

127. Nickels K, Wirrell E: Electrical Status Epilepticus in Sleep. Semin Pediatr Neurol 2008, 15:50-60.

128. De Tiège X, Goldman S, Verheulpen D, Aeby A, Poznanski N, Van Bogaert P: oexistence of idiopathic rolandic epilepsy and CSWS in two families. Epilepsia, 10 2006, 47:1723-7.
129. Gastaut H: A new type of epilepsy: benign partial epilepsy of childhood with occipital spike-waves. Clin Electroencephalogr 1982, 13(1):13-22.

130. Panayiotopoulos CP: Panayiotopoulos syndrome: a common and benign childhood epileptic syndrome. London: John Libbey \& Company Ltd; 2002.

131. Gastaut H, Roger J, Bureau M: Benign epilepsy of childhood with occipital paroxysms. Up-date. In Epileptic syndromes in infancy, childhood and adolescence. Edited by: Roger J, Bureau M, Dravet C, Dreifuss FE, Perret A, Wolf P. London: John Libbey 1992:201-17.

132. Tenembaum S, Deonna T, Fejerman N, Medina C, Ingvar-Maeder M, GubserMercati D: Continuous spike-waves and dementia in childhood epilepsy with occipital paroxysms. J Epilepsy 1997, 10:139-45.

133. Verrotti A, Parisi P, Loiacono G, Mohn A, Grosso S, Balestri P, Tozzi E, lannetti P, Chiarelli F, Curatolo P: Levetiracetam monotherapy for childhood occipital epilepsy of gastaut. Acta Neurol Scand 2009, 120(5):342-6.

134. Grosso S, Vivarelli R, Gobbi G, Di Bartolo R, Berardi R, Balestri P: Late-onset childhood occipital epilepsy (Gastaut type): a family study. Eur J Paediatr Neurol 2008, 12(5):421-6.

135. Striano S, Capovilla G, Sofia V, Romeo A, Rubboli G, Striano P, Trenité DK: Eyelid myoclonia with absences (Jeavons syndrome): a well-defined idiopathic generalized epilepsy syndrome or a spectrum of photosensitive conditions? Epilepsia 2009, 50(Suppl 5):15-9.

136. Covanis A: Photosensitivity in idiopathic generalized epilepsies. Epilepsia 2005, 46(Suppl 9):67-72.

doi:10.1186/1824-7288-37-58

Cite this article as: Parisi et al:: "Electro-clinical Syndromes" with onset in Paediatric Age: the highlights of the clinical-EEG, genetic and therapeutic advances. Italian Journal of Pediatrics 2011 37:58.

\section{Submit your next manuscript to BioMed Central and take full advantage of:}

- Convenient online submission

- Thorough peer review

- No space constraints or color figure charges

- Immediate publication on acceptance

- Inclusion in PubMed, CAS, Scopus and Google Scholar

- Research which is freely available for redistribution

Submit your manuscript at www.biomedcentral.com/submit
C Biomed Central 